\title{
BASILAR IMPRESSION OF THE SKULL
}

\author{
BY \\ A. DE VET \\ From the Neurological and Neurosurgical Clinic of St. Ursula, The Hague (Wassenaar), Holland. \\ Read at the 25th meeting of the Society of British Neurological Surgeons, Manchester, \\ November 1937.
}

\section{(ReCEIVED 29TH November, 1939)}

THE anatomical features of basilar impression of the skull have long been known; its recognition during the lifetime of the patient is extremely difficult on clinical grounds alone, and must be based on accurate radiological examination. In the case to be described in the present paper, planigraphic radiography by the method of Dr. Ziedses Des Plantes (1932) clarified the anatomical details and proved a most reliable aid to diagnosis.

\section{Anatomy and atiology}

In basilar impression the bony margin of the foramen magnum, together with the adjacent parts of the occipital bone, are pressed into the cranial cavity, so that the clivus, which normally takes an almost vertical course from the dorsum sellæ to the anterior margin of the foramen magnum, is elevated to assume a horizontal or even a reversed direction. The angle between the clivus and the planum sphenoidale, varying between $110^{\circ}$ to $140^{\circ}$ in normal skulls, approaches or exceeds $180^{\circ}$. The vertebral column follows the foramen magnum into the skull so that the axis, remaining in its position between the lateral masses of the atlas, may arrive at, or above, the level of the sella turcica. Abnormal pressure conditions cause skeletal atrophy, and the bony margin of the foramen magnum and the adjacent bone may become paper-thin. The arches of the atlas are subjected to abnormal pressure, and in severe cases even the axis may show pressure atrophy. As a rule the other bones of the skull do not show any abnormalities, but the cervical vertebræ may be malformed or fused.

The first anatomical description appeared at the end of the eighteenth century. A relationship was sought between rickets, cretinism, and basilar impression (Ackermann et al.). Rokitansky attributed an ætiological significance to the hydrocephalus present in his cases. Virchow (1877) established the final anatomical picture, based on his own observations and a comprehensive review of the literature, which were extensive even in those days. Virchow excluded rickets, cretinism, hydrocephalus, idiopathic and puerperal osteomalacia (Lucae, 1857; Berg and Retzius), and senile atrophy as causes of 
the condition, attributing to them an incidental ætiological significance only. He was impressed by the facts pointing to a geographical distribution of the disorder and stressed the importance of congenital or racial factors. Basilar impression appeared to be more common in Friesland, along the Dutch coast, and in the Bremen district. The frequent co-existence of congenital malformations, particularly those of the hip (Grawitz, 1880), lent support to this view.

In Paget's disease a condition similar to basilar impression may occur. Marie and Léri (1913) described it under the name of "convexobasie," and later Grunthal (1931) and Hanser (1926) reported cases of Paget's disease presenting clinical symptoms identical with those in genuine basilar impression. The two conditions may, however, be distinguished by the appearance of the base of the skull, particularly the margins of the foramen magnum, which are thickened in Paget's disease but atrophic in basilar impression.

Other skeletal abnormalities have been thought to be related with basilar impression. Schüller (1911) mentioned dysostosis cleidocranialis, bathocephaly, in addition to Paget's disease, as favouring its development. $\mathrm{He}$ interpreted the X-rays of his own two cases as showing rudimentary formation of the atlas and axis and fusion of the former with the occiput. The relationship between atlanto-occipital fusion and basilar impression was further discussed by Rose and also by Heidsieck. The two conditions frequently coexist, but the atrophic and commonly partial fusions which accompany basilar impression should, with Virchow, be regarded as secondary conditions. They differ from true union of the atlas with the occiput, which, according to Chiarugi (1890) and Bolk (1906) is due to embryological variations in the border between skull and vertebral column.

Attempts have been made by a number of authors to establish a connection between basilar impression and the syndrome of Klippel-Feil. Madame Dejerine * (1926) reporting a case of basilar impression with extensive hydromyelia regarded the condition as congenital, presenting the appearances normally seen in a $40 \mathrm{~mm}$. fotus. According to the same author, failure of the arches of the cervical vertebræ to close at that stage results in Klippel-Feil's abnormality, and although the cervical arches were completely normal in her own case, she concluded that an intimate embryological relationship existed between the two conditions.

A combination of the syndrome of Klippel-Feil with basilar impression was thought by Merio and Risak to have been present in three personally observed cases. The clinical and radiological features, as reported by the authors, are not at all convincing; the case with the most marked vertebral anomalies had no basilar impression.

Sekir concluded that the two disorders originated from the same developmental defect; from a growth disturbance of the "parachordalia." These are the mesenchymal elements which form the vertebral column and the os tribasilare, and Sekir stressed the important fact that only those bones at the base of the skull which are derived from the parachordalia are affected in

* Mme. Dejerine described this case under the name of " dystrophie osseuse," apparently unaware of the fact that the condition had previously been reported. 
basilar impression. Apart from embryological considerations, he based his conception on Mme. Dejerine's hypothesis and on the cases reported by Merio and Risak. Sekir's theory is attractive and more attention will have to be paid in future to abnormalities of the vertebral column in cases of basilar impression.

The fact is that the two conditions have never, so far, been proved to coexist. In basilar impression normally formed bone comes to occupy an abnormal position where it is subjected to atrophic changes; in Klippel-Feil's syndrome the bony defects and fusions, the outstanding features, are primary.

Lordosis of the cervical spine is another vertebral anomaly frequently encountered in basilar impression. Its presence may be revealed by palpation of the pharynx.

\section{The clinical manifestations of basilar impression}

A personally observed case may serve as an introduction to the clinical discussion of the disorder.

Mrs. G. R., aged 36. She had been in good health until the age of 19 , when for several weeks she suffered from a feverish illness with double vision and slight psychical

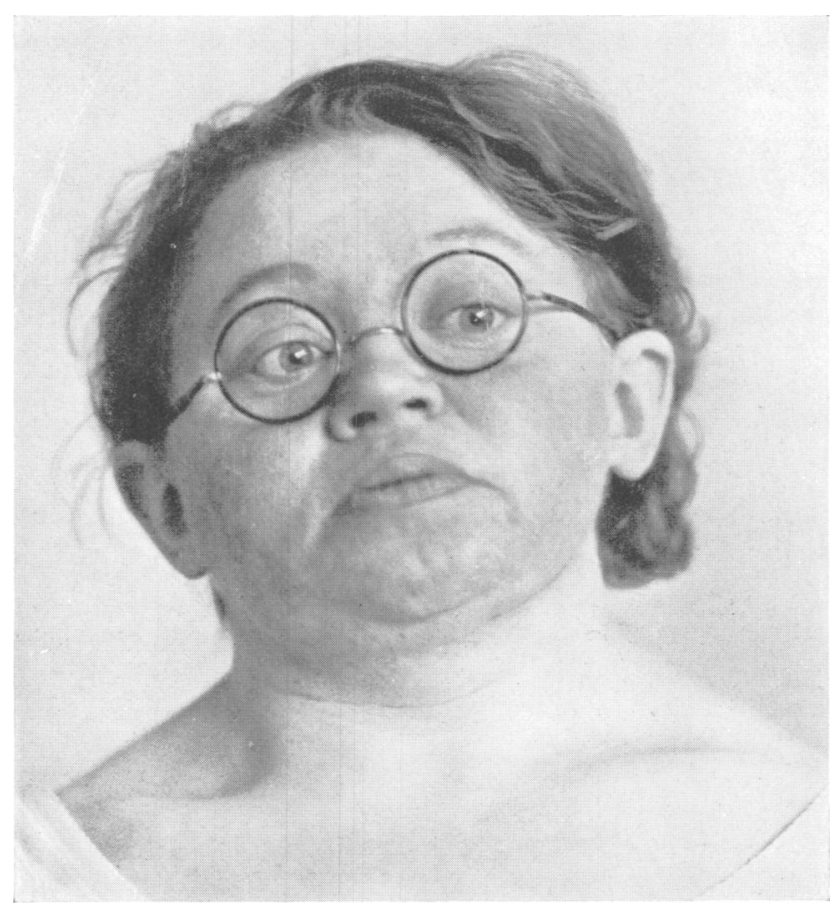

Fig. 1.

disturbances. She felt as if she were living in a dream, but was not lethargic. There were neither sensory nor motor disturbances. During the illness she frequently suffered from headache, which in later years troubled her only occasionally. Slight exophthalmos, noticeable in childhood photographs, increased dúring the illness, and 
nystagmus was observed by her relatives. Recovery was slow. Her gait was unsteady when she first got up, and although it improved, it never became quite normal again. Unsteadiness of her hands followed the illness, and still persists. A severe eczema affected her face and neck during her convalescence. Double vision persisted for 2-3 years and then entirely disappeared.

$2 \frac{1}{2}$ years ago the patient married, and until the birth of a normal child, 8 months before her admission to hospital, her condition remained unchanged. In the last 8 months, however, she became irritable, emotionally hyperexcitable, and often wept without apparent reason. Her memory failed, she was unable to think clearly, and she easily tired both mentally and physically, so that she could no longer do her household duties. She complained of tinnitus in the left ear, but not of deafness. She was seen by a neurologist, who suspected the presence of a posterior fossa tumour, and on the 26th August, 1936, she was admitted to hospital.

Since early childhood, it was learnt later, her head has been implanted on her shoulders in a curious manner. It always remained in a somewhat stiff attitude and the movements of the head and neck were restricted. The illness at the age of 19 did not influence the condition, but some years ago bending the head backwards gave rise to a painful sensation, to a sudden inability to move the head, and to giddiness. These attacks forced her to lie down flat and lasted for about $\frac{1}{4}$ hour.

Recently the patient had become fatter, particularly around the hips. Menstruation, irregular before her marriage, has been regular since. She did not complain of failing vision or diplopia, was not troubled by nausea or vomiting, and only occasionally suffered from headache.

No other member of the family suffered from a similar condition or from other congenital abnormalities. One nephew is schizophrenic.

Examination.-She is a short squat woman with an overdevelopment of fat around the hips. The mammary glands are within normal limits. The neck is abnormally shaped, the trapezius muscles are large. The neck is so short that the brachycephalic head appears to rest on the shoulders, and hardly one finger can be inserted between the occiput and the vertebra prominens. Neither the occiput nor the vertebral column are tender to pressure. All movements of the head, particularly extension, are restricted by the shortness of the neck, and the head is kept in an attitude of slight flexion. There is a scoliosis of the lumbar spine, convex to the left, and a marked lordosis.

The hands and the right foot are normal, but the second and third toes of the left foot are abnormally long.

Nervous System.-There is optokinetic nystagmus of a moderate degree in both directions, a coarse horizontal nystagmus to the right and left, and a vertical nystagmus on looking upward. Very slight expressional weakness of the right side of the face; the other cranial nerves are normal. The tongue, irregularly shaped and large, shows involuntary movements. On performing Romberg's test she shows a tendency to go to the right. The motor and sensory functions of trunk and limbs are normal. The abdominal reflexes are absent on both sides, and both plantar reflexes are indeterminate, showing an occasional tendency to be extensor. Other reflexes normal. Gait is unsteady, without selective deviation to the right or left. Very slight ataxia and dysdiadochokinesis are the only cerebellar signs.

The respiratory, digestive, and urinary systems are normal. The blood pressure is $170 / 105$, but the heart shows no abnormal features.

The lumbar cerebrospinal fluid pressure is $160 \mathrm{~mm}$. water and rises to $300 \mathrm{~mm}$. on jugular compression. Both rise and fall of the fluid level are slow. The cerebrospinal fluid contains $41 \mathrm{mgrm}$. per cent. protein, but is otherwise entirely normal. W.R. negative in blood and C.S.F.

Blood count and blood chemistry (calcium, phosphorus, cholesterol) are normal, as is the basal metabolic rate. 
Some clinical features peculiar to the present case warrant special comment. Exophthalmos is unusual in basilar impression, and in the present case no cause could be found for it. In two similar cases reported in the literature a colloid goitre (Stenvers, 1928) in one and familial disposition in the other (Biemond), were thought to be the cause of the exophthalmos.

The illness at the age of 19 may have been an atypical encephalitis or the first manifestation of the basilar impression. The latter view is supported by the apparent tendency of the condition to cause clinical signs about puberty and in the presenium (Sinz, Sekir). A new set of symptoms was provoked by the patient's pregnancy; the change in calcium metabolism accompanying pregnancy may have been the exciting factor. Apart from cases of puerperal osteomalcia (Lucae) effects of pregnancy on the course of basilar impression have not been reported.

The fact that the peculiar position of the head was present since childhood argues in favour of a congenital origin of the abnormality; it may be cited against Schüller's assumption that the condition develops within the course of a few years in young persons. If basilar impression is considered to be congenital the gradual or sudden appearance of symptoms in later life must be due to a disturbance of the intracranial equilibrium in the presence of abnormal anatomical conditions. Metabolic and endocrine variations which normally occur during puberty, pregnancy, and the puerperium may, by their effect on the structure of bone, lead to an increase of the basilar impression. Similar observations have been made in Paget's disease, puerperal and idiopathic osteomalacia, and in senile osteoporosis. Infectious diseases may also disturb the cerebrospinal fluid circulation, and although cranial trauma has never been proved to be an important factor, the habitual carrying of heavy loads on the head and neck might provoke a basilar impression in individuals in whom the disease previously existed, as it were, " in anlage."

The cases reported in the literature bear testimony to the difficulties presented by the clinical diagnosis. Boogaard was the first to describe the symptomatology of the condition.* He was followed by Schüller in 1911, who reported two cases, the first to be diagnosed with the aid of $\mathrm{X}$-rays during the patients' lifetime. Schüller classified the signs as due to:

(1) Irritation of cranial nerves in the posterior fossa by traction or pressure.

(2) Blockage of the cerebrospinal fluid circulation.

(3) Pressure on the medulla and cerebellum.

These signs may easily lead the observer to suspect the presence of a posterior fossa tumour, but a variety of other conditions have been wrongly diagnosed in patients suffering from basilar impression. In Stenver's (1928) case hydrocephalic dilatation of the infundibulum had during the patient's lifetime given rise to homonymous hemianopia and dystrophia adiposogenitalis with amenorrhœa, so that the presence of a pituitary adenoma had been suspected. Disturbances of endocrine secretion were also described by Merio and Risak.

\footnotetext{
* The first of many Dutch papers was by Vrolik.
} 
Astereognosis in both hands, which later became paralysed, was an unusual feature of the case reported by Rose. Glial hyperplasia and cyst formation of the posterior columns was found at necropsy. Mme. Dejerine's patient suffered from tachycardia and rapid respirations in addition to dysphagia and paralysis of the left side of the palate. A psychological disorder may have complicated the clinical picture in this case. Kecht (1932) wrongly diagnosed syphilis in his patient; De Morsier and Junet (1936), Bodechtel and Guizetti (1933) mistook cases of basilar impression for cases of posterior fossa tumours, and in one of his four cases Ebenius (1934) diagnosed a tumour of the quadrigeminal plate.

\section{Radiological diagnosis}

The clinical signs presented by basilar impression are by no means characteristic of that condition alone, and even the absence or extreme shortness of the neck is not pathognomic, for it may be found in Klippel-Feil's syndrome and in Pott's disease of the cervical spine. These difficulties may be overcome by the study of accurate X-ray pictures. Unless special attention is paid to the condition of the base of the skull, the abnormality may be overlooked. In two cases reported in the literature (Kecht, Ebenius) scrutiny of the films after necropsy revealed evidence of the disorder which had previously been missed.

In the present case the "impression" was unusually far advanced so that the odontoid process and the lateral masses of the atlas could be clearly seen on the ordinary antero-posterior view. This finding alone established the diagnosis. Should the odontoid process and the atlas be lower, the ordinary lateral skiagrams would not be helpful, for then the atlas and the axis would be concealed by the petrous bones. In these less severe degrees of basilar impression only the sagittal planigram can give a clear anatomical picture of the deformity.

The planigrams of the present case need little comment. The sagittal section shows the upward direction of the clivus, behind it the anterior arch of the atlas and the odontoid process. The posterior arch of the atlas is on a lower level, so that the plane of the atlas is oblique. The occipital squama is also oblique, a feature absent in slight or moderate cases. The obliquity of the atlas allows the deduction that the anterior margin of the foramen magnum must be higher than the posterior.

Vertebral abnormalities can be diagnosed with much more certainty on planigrams than on ordinary films. In the present case the cervical spine was markedly lordotic, but apart from atrophy of the posterior arch of the atlas, which in all probability was fused with the occiput, the structure of the cervical vertebræ was normal. In the lower parts of the vertebral column the 3rd, 4th, and 5th thoracic vertebræ were partly fused and the intervertebral discs in the lower dorsal spine had an oval shape. The lumbar spine was markedly lordotic and scoliotic with a convexity to the left. Abnormal shape of the lower two lumbar vertebræ, the upper part of the sacrum, and both sacro-iliacj oints were present. 


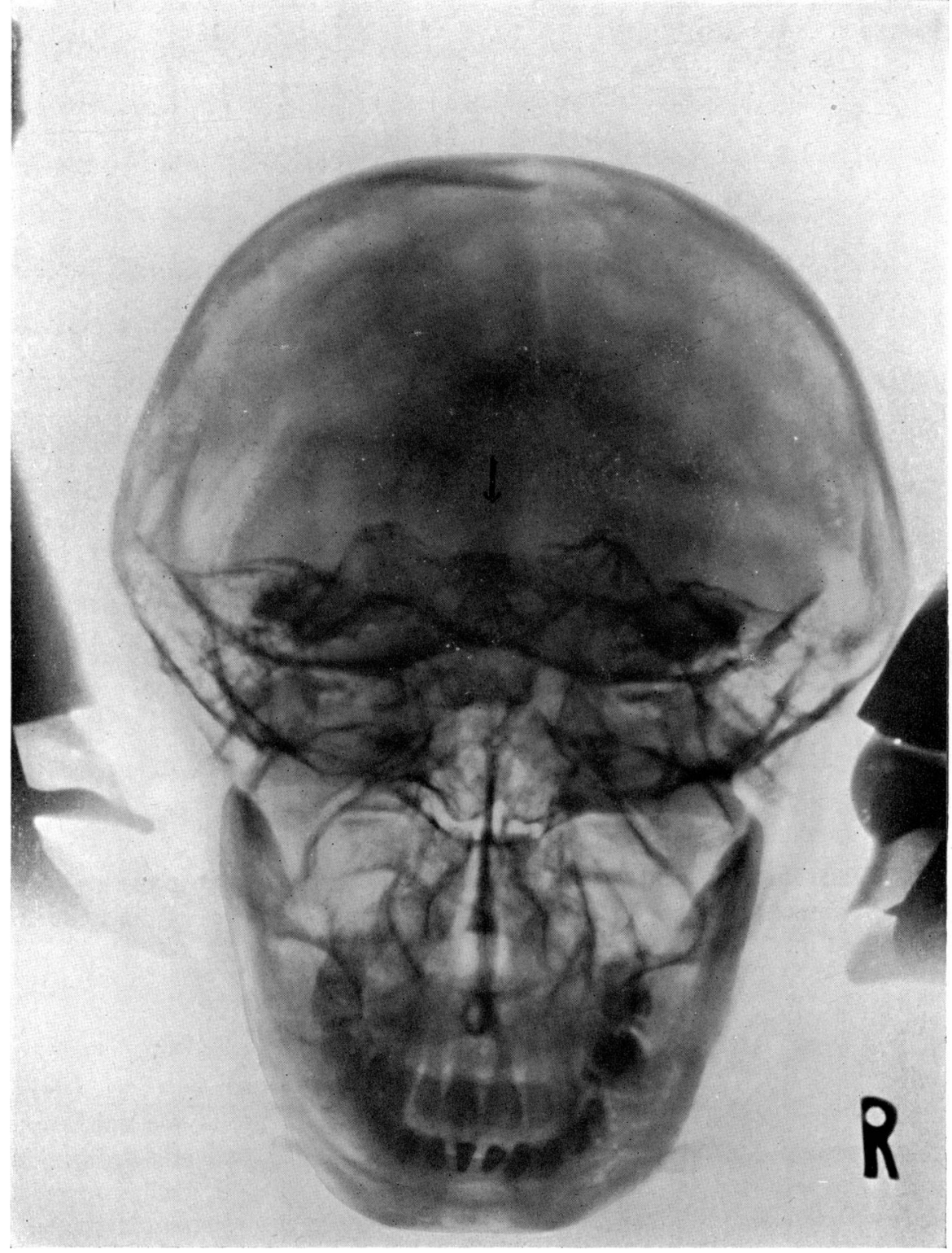

Fig. 2.-Antero-posterior view of the skull; the arrow indicates the odontoid process. 


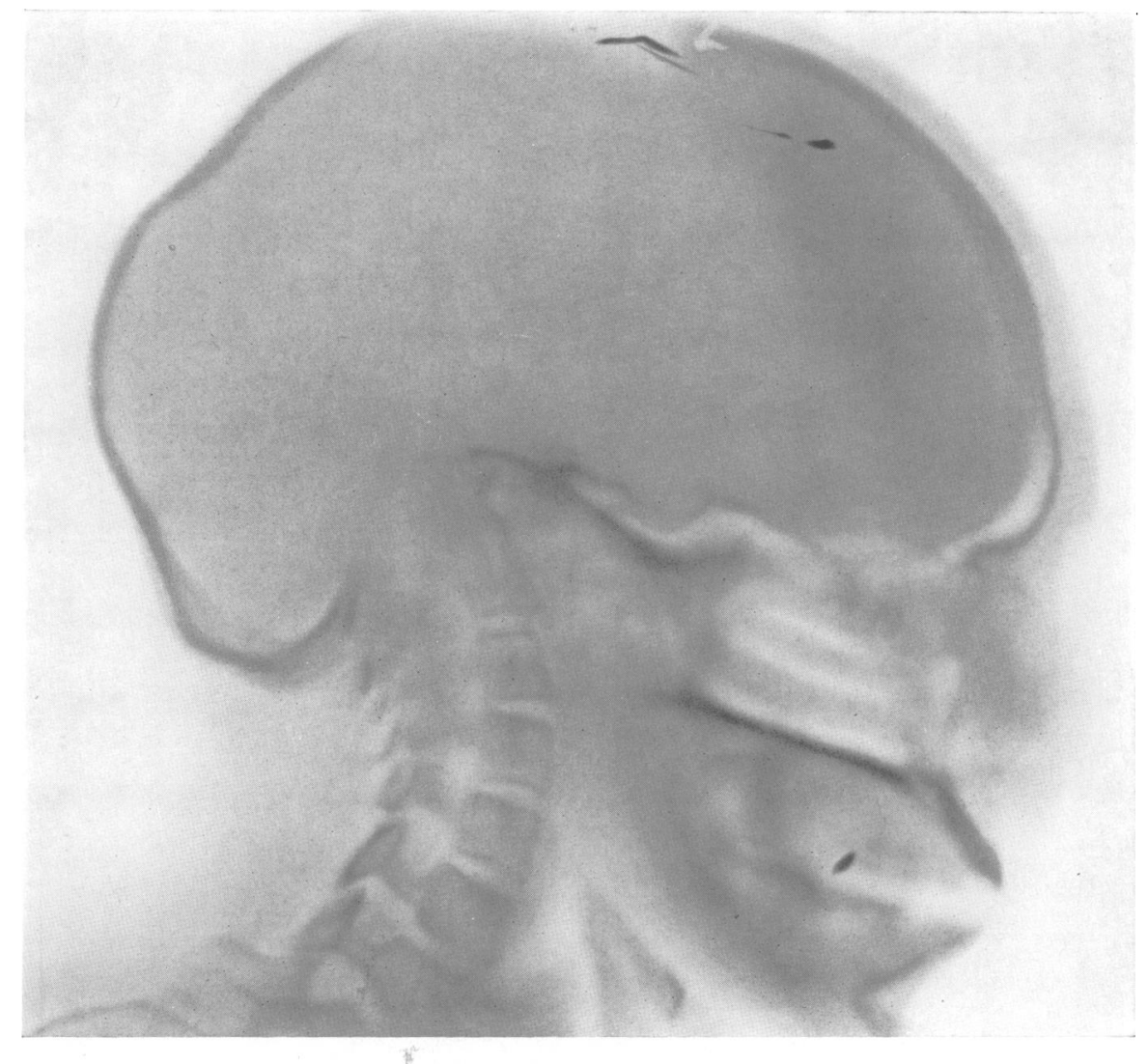

Fig. 3.-Sagittal planigraphic radiogram (method Dr. Ziedses Des Plantes.)

The fact that the cervical spine was normal excludes the presence of a Klippel-Feil deformity in this case, and the other abnormalities of the spine do not suggest it.

\section{Treatment}

Little attention has so far been paid to the treatment of the condition, chiefly because it has rarely been diagnosed before the patient's death. In three cases reported by Ebenius suboccipital decompression was performed. His cases were not far advanced and the operation therefore presented no technical difficulties. It might well be different in severe cases of impression. Apart from technical difficulties and the fact that decompression is only symptomatic treatment, one must consider the possible acceleration of the course of the abnormality after the removal of a large portion of the occipital bone. Under normal conditions the bone which is removed has no supporting function, but in basilar impression the normal planes of support fail and are replaced by 
others (Schüller). The posterior arch of the atlas and the posterior margin of the foramen magnum may participate in this function.

A more rational form of treatment was suggested by Sekir, who advocated the use of a supporting apparatus for the head and neck. In the present author's opinion traction on the head by one of the methods in common use ought to prove more efficient. This form of treatment might be followed by the use of a supporting apparatus, once the progress of the disorder has been halted and the patient's condition has been improved. Suboccipital decompression should be reserved for patients who show definite signs of increased intracranial tension.

The patient described in the present paper improved with rest so that no special treatment appeared indicated. She remains under observation and will be re-admitted for more active treatment should her condition deteriorate.

\section{Summary}

The anatomy of basilar impression is described. The ætiology of the malformations and its relationship to other skeletal abnormalities is discussed.

One personally observed case is reported, its special features commented on.

The literature on the clinical symptomatology of the condition is summarized.

The value of X-ray diagnosis, particularly planigraphy, is stressed.

The treatment of the condition is discussed.

I am indebted to Dr. Ziedses Des Plantes of Utrecht for the X-rays of the present case. The planigraphic films were taken after his own method.

(For References see p. 250) 


\section{REFERENCES}

Bodechtel, G., and Guizetti, H. U. (1933). Z. Neurol. Psychiat., 143, 470.

Bolk, L. (1906). Anat. Anz., 28, 497.

Chiarugi G. (1800). Monit. zool. ital., 1.

Déjérine, J. (1926). Rev. Neurol., 4, 281.

Ebenius, B. (1934). Acta radiol. Stockh., 652.

Grawitz, P. (1880). Virchows Arch., 80, 449.

Grünthal, E. (1931). Z. Neurol. Psychiat., 136, 656.

Hanser, R. (1926). Verh. dtsch. path. Ges., 21, 103.

Kecht, B. (1932). Z. Neurol. Psychiat., 141, 132.

Lucae, J. C. G. (1857). Zur Architectur des Menschenschädels, nebst geometrischen Originalzeichnungen von Schädeln normaler und abnormer Form. Frankf. a.M.

Marie, P., and Léri, A. (1913). Handb. Neurol. Lewandowsky, 4, 471.

Morsier, G. de, and Junet, R. (1936). Rev. Neurol., 65, 1483.

Schüller, A. (1911). Wien med. Wschr., 41, 2593.

Stenvers, H. W. (1928). Röntgenoligie des Felsenbeines und des bitemporalen Schadelbildes. Springer, Berlin.

Virchow, R. (1877). Physischen Anthropologie der Deutschen. Berlin.

Ziedses des Plantes, B. G. (1932). Acta radiol. Stockh., 13, 182.

Note.-Owing to the war it has not been possible to obtain a complete list of references. 